\title{
Spiritual Distress In Breast Cancer Patients
}

\author{
Pujilestari, Aan Nuraeni, Dyah Setyorini \\ Faculty of Nursing, Universitas Padjadjadjaran \\ Email:Puji120031@gmail.com
}

\begin{abstract}
Breast Cancer would affect all aspects of patients' life including spiritually. This aspect is one of the patients' main coping sources in dealing with impacts of the disease. However, the spiritual aspect is rarely noticed by nurses, and may lead to patients' spiritual distress. This study aimed to determine spiritual distress in breast cancer patients who had treatments in a referral hospital in West Java. This study was a descriptive quantitative with cross-sectional approach. The population was in-patient breast cancer patients. Respondents were chosen using the accidental sampling technique. During a month period, 37 patients involved in this study. The data was collected using an instrument which was developed from Spiritual Distress Assessment Tool (SDAT) and analyzed using descriptive quantitative analysis. Almost two-thirds (62.2\%) of respondents had low spiritual distress, 32.2\% of respondents had moderate spiritual distress and a very small number of respondents $(5.4 \%)$ had severe spiritual distress. In the term of spiritual distress dimension, "life balance" had the highest mean score (1.86) and the lowest was in "values and beliefs with sub-dimension of need maintain control" (0.89). The conclusion was the majority of patients had low spiritual distress, yet spiritual distress for moderate to severe still could be found in smaller proportion. Life balance was dimension with the highest level of spiritual distress. The patients' spiritual need would be achieved when patients have a good acceptance and adaptation. Nurses have a role to encourage patients' acceptance of their illnesses through improvement of the fulfillment of the patient's spiritul needs.
\end{abstract}

Keywords: Breast cancer, distress, spiritual. 
Puji Lestari : Spiritual Distress in Breast Cancer Patients

\section{Introduction}

Breast cancer was the most common cancer in women and the number one cause of women's mortality worldwide (WHO, 2012). The data from the International Agency for Research on Cancer (IARC) in 2012 revealed that breast cancer was cancer with the highest incidence, which was $43.3 \%$ and the percentage of deaths caused by breast cancer was $12.9 \%$. WHO data (2012) stated $21.4 \%$ of 92,200 women's death in Indonesia were caused by breast cancer.

Breast cancer would cause changes both physically and psychologically to the patients or also known as distress. Distress is an abnormality due to a person's inability to adapt to physical and mental changes that would interfere with their comfort and productivity (Manning-Walsh, 2005). The physical distress of breast cancer patients includes chronic pain, fatigue, nausea and vomiting, loss of appetite, sleep disturbance, body image disorder, and others (Jafari et al., 2013). Breast cancer treatments would also affect patients' psychological. Jafari et al. (2013) stated that patients who were in treatment or therapy had worse psychic symptoms and social dysfunction than those who did not perform breast cancer treatment. The social dysfunction impacted patients' ability to express their helplessness and anxious feeling, if patients could not overcome with these situations they were at a risk of feeling depressed. Breast cancer patients who could not cope with their anxiety with a positive coping strategy would fall into the depression stage that could have a negative effect on their health (Siregar \& Muslimah, 2014). Depression and anxiety that suffered by breast cancer patients were one of psychosocial distress.

One of the aspects that could help breast cancer patients to deal with distress is the spiritual aspect. Spiritual is the only hope for coping and healing source (Puchalski, Virani, Bull, \& Chochinov, 2009). A wellpreserved spirituality is an individual source to have a positive emotion (Fredrickson, 2004), which means it could be a healing for patients. On the other hand, as an individual might experience an imbalance situation, it called the spiritual distress. The spiritual distress occurred when the spiritual needs were not fulfilled optimally. Hatamipour, Rassouli, Yaghmaie, Zendedel, and Majd (2015) had an opinion that spiritual distress was a crisis that provokes imbalance of mind, body, and soul caused by loneliness feeling. When spiritual distress occurs, many aspects would be affected as the spiritual dimension is extensive. Spiritual distress became the negative source that would have an impact on the patient's health. This in line with the theory of Psychoneuroimmunology (PNI), Robins et al. (2013), that stated the negative thoughts or all kinds of stress would stimulate hormones that had an impact on decreased immunity. Spiritual distress in breast cancer patients would impact health deterioration both physically and psychologically.

Caldeira, Carvalho, and Vieira (2014) in Portugal studied of distress spiritual, they found that $42 \%$ of respondents experienced spiritual distress. This was not a small number and could not be ignored. They also mentioned that the characteristics of cancer patients who experienced spiritual distress had similar signs and symptoms to depression patients. Spirituality in general was an individual concern and varies depending on race and ethnicity. In Indonesia, the aspect of spirituality was strongly influenced by the community culture, especially for Muslim (Nur'aeni, Ibrahim, \& Agustina, 2013). This became one of the factors that could increase spirituality and prevent spiritual distress, but this opinion needed to be assessed further. Spiritual distress is an uncertain matter. The differences in culture background were not the only one factors that affect spiritual distress. In addition, there were also big differences in health services in developed countries and in Indonesia as a developing country. Those descriptions were a background that spiritual distress should assess more because there were not many publications available in Indonesia especially for breast cancer patients.

\section{Research Method}

This study applied descriptive quantitative research design to identify patients' spiritual distress. The population was all breast cancer 
Puji Lestari : Spiritual Distress in Breast Cancer Patients

patients who were hospitalized at one of the referral hospitals in West Java. The average of breast cancer patients who were hospitalized in this hospital was 41 patients each month. The samples were chosen using accidental sampling technique. During a month period, 37 patients involved in this study.

The data was collected using an instrument which was developed from Spiritual Distress Assessment Tool (SDAT). This instrument used to identify unfulfilled spiritual needs, knowing the level of spiritual distress both in general and in each dimension, designed by Monod et al. (2010). The spiritual needs include life balance, religious, value and faith, and social relationship. The Instrument consisted of 41 questions to measure spiritual distress and its four dimensions. This instrument scoring measured the fulfillment of spiritual needs by giving a score of 0-3 on each statement. This instrument has passed the validity and reliability test. The validity range was at $0.442-0.886$ with a reliability value of 0.914 . Data analysis used quantitative descriptive analysis which used the average score and frequency distribution.

Ethical Consideration

The ethical approval of this study obtained through the Decree of the Ethical Agreement Recommendation Number. LB.04.01/A05/ EC/094/III/2016 issued by Health Research Ethics Committee of RSUP. Dr. Hasan Sadikin Bandung. All respondents in this study had obtained informed consent and voluntarily participated.

\section{Research Results}

This study found that the majority of respondents were in the range of 50-59 years $(45.9 \%)$ and attended secondary education $(32.4 \%)$. Respondents were married $(94.6 \%)$ and most of them are Muslim (94.6\%). Most of the respondents are Sundanese (86.5\%).

Figure 1 reveals that the majority of respondents had mild spiritual distress $(62.2 \%)$ which means that most of the

Table 1 Characteristics of Breast Cancer Respondents $(n=37)$

\begin{tabular}{lcc}
\hline \multicolumn{1}{c}{ Characteristic } & Frequency (f) & Percentage (\%) \\
\hline Age & 3 & 8.1 \\
$30-39$ & 10 & 27 \\
$40-49$ & 17 & 45.9 \\
$50-59$ & 6 & 16.2 \\
$60-69$ & 1 & 2.7 \\
$>70$ & & \\
Last Education & 3 & 8.1 \\
Did not attend school & 20 & 54 \\
Primary Education & 12 & 32.4 \\
Secondary Education & 2 & 5.4 \\
College & & \\
Religion & 35 & 94.6 \\
Islam & 2 & 5.4 \\
Christian & & \\
Marital Status & 35 & 94.6 \\
Married & 2 & 5.4 \\
Single & & \\
Cultural Background & 32 & 86.5 \\
Sundanese & 5 & 13.5 \\
Javanese & & \\
\hline & &
\end{tabular}




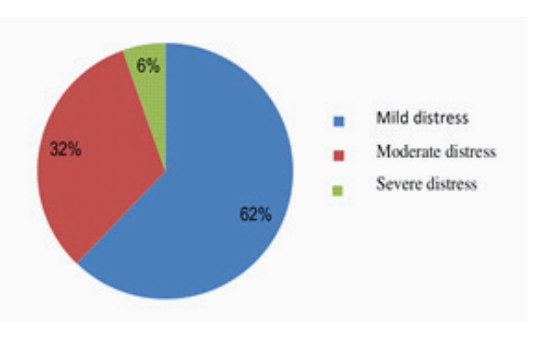

Figure 1 Spiritual distress in hospitalized breast cancer patients $(n=37)$

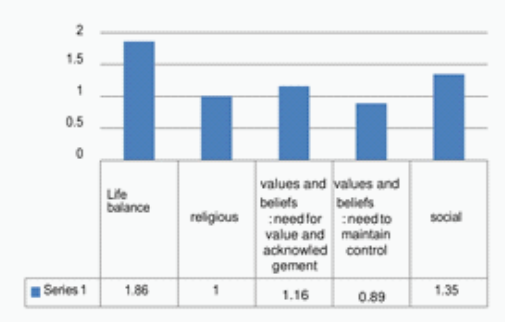

Figure 2 Stages of spiritual distress based on its dimensions in hospitalized breast cancer patients $(\mathbf{n}=37)$

patients' spiritual needs were well fulfilled. Other minorities had moderate distress $(32.4 \%)$ and severe distress $(5.4 \%)$.

This study found the level of spiritual distress based on its dimensions. This level was categorized from the average score of each dimension then ranked from the highest to the lowest. The level of spiritual distress of each dimension from the highest to the lowest among them were; dimensional balance of life (1.86), dimensions of social life (1.35), dimensions of sub-dimensional values and beliefs Need for value acknowledgment (1.16), religious dimension (1.00), dimensions of sub-dimensional values and beliefs to maintain control $(0.89)$.

\section{Discussion}

The spiritual aspect became the hope and source of healing for the individual (Puchalski, 2001). In the spiritual distress condition, the patient would lose hope, and there was no source of spirit that encourages the patient to survive. Monod et al. (2010) stated that spiritual distress was a condition where individuals experience a disturbance of the value system or beliefs that became the source of spirit and life. This study found that the majority of respondent had mild spiritual distress $(62.2 \%)$ and the rest experienced moderate to severe distress. This suggests that the majority of respondents experience mild spiritual distress but the occurrence of moderate to severe spiritual distress could not be ignored

The low level of spiritual distress respondents in this study would be caused by cultural background. Eastern society, Indonesia, has traditional values such as familyism, family as central, interdependence, maintaining harmony (Friedman, Bowden, \& Jones, 2003). In the traditional values, the need to be loved and being close with family could be met, so it affected the level patients' spiritual distress (Monod et al., 2010). Lu et al. (2013) revealed that the attention and affection of the family and being among the family would be a source of strength and happiness for individuals with chronic illness. Most respondents had a spouse and patients 
Puji Lestari : Spiritual Distress in Breast Cancer Patients

were accompanied by their spouse and family even though they were inpatient. This shows that family is still an important source for Indonesian. This may help in decreasing patient's distress level, as the family became a source of spirit, strength and happiness for the patient so it meets the patient's need to be loved and be close in the family.

Indonesian society was identical with religious society (Nur'aeni et al., 2013). Religion or belief in God was one source of strength of an individual, especially cancer patients. This disease was a way that makes them closer to God (Ahmad, Binti Muhammad, \& Abdullah, 2011). The culture of religiosity affected patients would meet their spiritual needs. Patients' practices their religion ritual activities when they were hospitalized with many limitations such as the difficulty of making movements and difficulty of self-cleansing. Religion was a spirit source for the patient, the belief in God helped the patients to get the peace and tranquility of their heart and took the positive side of hardship lives.

The positive coping is shown when patients were tested with an illness they still show their gratefulness to God. Nur'aeni et al. (2013) mentioned that by thinking positively patient perceived that the pain they experienced was the test and the love of God them. These were the reasons why the majority of respondents have a mild degree of spiritual distress, in contrast to the incidence of spiritual distress outside of Indonesia whose respondents are in need of antidepressant medication. The affection of the family, good religiosity and positive thinking, the level of spiritual distress of the patient would be reduced because the patient had many sources of spirit in their life. This in line with the study finding that indicated that most respondents have a low level of spiritual distress that indicates that some of the spiritual needs of respondents have been met.

This study found patients with moderate to severe distress $(38.8 \%)$ which could not be ignored. In moderate to severe distress, most of the spiritual needs were not met. Monod et al. (2010) indicated that spiritual needs include the dimensions of the balance of life, religion, values and beliefs, and social relationships. Everyone had needs that must be met in each dimension but would differ in which dimension was the most influential to spiritual distress.

The study findings revealed that the dimension of life balance was the dimension with the highest level of distress. In this dimension, an individual needs selfacceptance of illness and self-control of the disease impact on the individual life (Monod et al., 2010). Personal acceptance of the illness was influenced by internal factor. A theory proposed by Alfred Adler suggested that a physical disability or a disease would develop a sense of inferiority within a person. Inferiority is a feeling where the individual felt weak and helpless. Walton (2002) stated that balance in life is when an aspect of life is disturbed but other aspects covered it up, so the individual feels prosperous with the situation. In the early stages, the individual would feel pain as a burden, then the individual would adapt and start to things the positive and negative of diseases, finally the individual is turning the negative perception into a positive perspective (Nur'aeni et al., 2013).

The inferiority and weakness of the individual would frustrate the capability to turn a negative perception into a positive outlook, then affected individual's psychic and physical aspects. If the patients met their needs of the balance life aspect, they should be able to adjust so it reduces the negative impact of the disease on her life. This study found that the majority of patients felt disturbed in everyday aspects; felt lazy to eat, disturbed sleep patterns, felt ashamed of their illness and disrupted the role of family members. This showed that the needs in the aspect of life balance could not be fulfilled because of cancer and negative impact on the daily life of the individual resulting in a spiritual distress for the patient.

The dimension of life balance was the highest-level dimension the of spiritual distress because the need for this dimension is broad, for example controlling the impact of the disease on all aspects, if the impact of the disease getting broad on the daily life of the patient, there would be more needs that 
Puji Lestari : Spiritual Distress in Breast Cancer Patients

could not be fulfilled. The impact would be a higher level of spiritual distress of this dimension.

The dimension which has the second highest level of distress was the dimension of social relations. Relationships with others or social aspects were aspects that also play a role in influencing one's spirituality. Monod et al. (2010) stated that in the dimension of social relations an individual had a need to love and be loved and be in the midst of their beloved. However, one's social relationships did not always work well, there were some things related to the bad social relations of one of them was that there were misunderstandings and individual characters that were not empathetic to the environment $(\mathrm{Ku}, 2005)$. This is in agreement with the study findings that the most distress in this dimension was the concern the family that they would be bored to assist respondents. Although social support was good, if the individual isolated themselves from social or had a misunderstanding of the environment then the need for spirituality to get love and affection from social would be un met.

In breast cancer patients, physical changes made patients being not confident and felt ashamed of her condition. Patients tend to isolate themselves from their environment which affected the social interaction (Siregar \& Muslimah, 2014). The low social interaction, the patient was unable to express her helplessness, so that the patients would isolate herself and would feel unloved and shunned by the people around her. Whereas the affection of those around the patient would be a source of spirit, the patient's need to be loved would not be fulfilled and this might affect the patient's spiritual aspect and the patient experiencing spiritual distress from the social relations dimension.

Nurses as the most often health care officers who interact with patients are expected to have an active role in providing spiritual nursing care that has been less a concern. Some burdens of nursing care in the spiritual aspect were perspectives that spiritual aspects were a privacy for patients so they felt uncomfortable to discuss it, another obstacle was differences in values, beliefs and cultures between nurses and patients so that the nurse was having difficulties to talk about spirituality (Vance, 2001). The cultural background becomes a challenge that influences one's characteristic. In Sundanese culture, the Sundanese people are always respecting others above their own personal lives to maintain good relations with others. In this culture when an individual does not like something, they would not express respect for others (Muhsin, 2011). The nurse could establish a trust with the patients by listening to them, when they expressed their feelings, always being friendly to the patients and the patient might be gradually exposed and able to express the perceived of discomfort. When the patient is open to a nurse, the nurse would facilitate the patient's needs so it would decrease the level of spiritual distress.

The dimension that has the third highest level of distress was the dimension of values and beliefs, sub-dimension needs for value acknowledgment. The spiritual needs in this dimension were respected by health care workers related to their spiritual and believe (Monod et al., 2010). This might due to the roles of health workers were less in the spiritual care. The less of spiritual care might due to nurses only have limited time with patients because of the number of patients who were not comparable with the available nurses (Vance, 2001). This in line with these study findings that the poorest component in this dimension was the role of health workers who did not help and facilitate patients' religion practices. Deal and Grassley (2012) mentioned that the nursing interventions as spiritual nursing care were to facilitate both the facilities and the implementation patients' religion practices. In fact, it was less accommodated by health professionals, so the need of patients to have religion practices were not met, and would increase the possibility of spiritual distress, especially from the religious dimension.

The fourth and fifth dimensions are the bottom two dimensions that have the lowest level of distress among the other three dimensions. The fourth dimension is the religious dimension. This dimension discussed the individual relationship with God. As mentioned earlier in factors that would increase spiritual distress, the cultural 
Puji Lestari : Spiritual Distress in Breast Cancer Patients

background of Indonesia attached to divinity is one of the sources of power possessed by individuals (Ahmad et al., 2011). If religious needs cannot be met it would be a source of stress for patients. This is in line with what Ku's (2005) study that some things that would cause patients' distress from the religious aspect, such as; inability to perform religious rituals and unable to engage in religious activities.

The last dimension that has the lowest level of distress is the dimension value and sub dimensional Need to mantain control. This dimension addressed the individual's need in their involvement in making decisions based on their values and beliefs (Monod et al., 2010). This was greatly influenced by the informed consent provided by health workers such as doctors and nurses. Keating, Weeks, Borbas, and Guadagnoli (2003) stated that informed consent was the patient or family's agreement about the action to be performed, health workers provide an advance explanation of the procedure information, the risk of action and no action, and the patient or family voluntary to refuse or accept the health intervention.

In Indonesia any invasive actions require written approval or informed consent as defined in Regulation of the Minister of Health No. 290/Men.Kes/Per/III/2008. The existence of obligations and the rule of law governing this. Health workers always gave informed consent before taking any health interventions, because health workers who performed actions without giving informed consent would get hard sanctions and consequences. By giving the informed consent, the patient would obtain information related to health interventions. In addition, patients involved in their treatment process either directly or indirectly to the decision making about the actions.

These study findings revealed the majority of respondents attended elementary school and some of them did not attend school, it means the majority of respondents had a low level of education. This was a factor that affects to the need to maintain control over the individual. Yuniarta and Suharto (2011) had an opinion with low levels of education, patients tend to entrust all actions to health workers, so patients assume that health workers know which was the best. Patients who had low levels of education did not really need dimension Need to mantain control because patients tend to entrust all the actions done to them. This is proven on this study results that $56 \%$ of patients only have mild disturbances even $24 \%$ have no interference at all in this dimension, which means most of the needs in this dimension were mostly met well. So, the patient's need to be involved in making decisions and being informed about the treatments would be met well and this dimension becomes the smallest dimension of their distress.

\section{Conclusion}

Nurses have a role as a care provider, nurses should treat the patient as a holistic entity. Improving the service of spiritual nursing care in the patient is needed so that the spiritual needs of the patient are met well. If the spiritual needs of the patient are not met well then it would cause spiritual distress, and it may impact deteriorate the health and quality of life of the patient. Spiritual needs in breast cancer patients in this study include life balance, transcendence (religious), values \& beliefs and social relationships. The majority of respondents had a mild degree of spiritual distress, which means that the majority of the patient's spiritual needs were well met. Based on the dimensions obtained, level of dimensions that have the highest distress to the lowest one among them; the dimension of life balance, the dimension of social life, dimensions of subdimensional values and beliefs Need for value acknowledgment, religious dimension, the dimension of subdimensional values and beliefs Need to mantain control.

\section{References}

Ahmad, F., Binti Muhammad, M., \& Abdullah, A. A. (2011). Religion and spirituality in coping with advanced breast cancer: Perspectives from Malaysian Muslim women. Journal of Religion and Health, 
Puji Lestari : Spiritual Distress in Breast Cancer Patients

$50(1), 36-45$.

Caldeira, S., Carvalho, E.C. de, \& Vieira, M. (2014). Between spiritual wellbeing and spiritual distress: Possible related factors in elderly patients with cancer. Revista LatinoAmericana de Enfermagem, 22(1), 28-34.

Deal, B., \& Grassley, J.S. (2012). The lived experience of giving spiritual care: A phenomenological study of nephrology nurses working in acute and chronic hemodialysis settings. Nephrology Nursing Journal, 39(6), 471.

Fredrickson, B.L. (2004). The broadenand-build theory of positive emotions. Philosophical Transactions of the Royal Society B: Biological Sciences, 359(1449), 1367.

Friedman, Bowden, \& Jones. (2003). Family nursing: Research, theory and practice $\left(5^{\text {th }}\right.$ Ed.). Stamford: Appelton \& Lange.

Hatamipour, K., Rassouli, M., Yaghmaie, F., Zendedel, K., \& Majd, H.A. (2015). Spiritual needs of cancer patients: A qualitative study. Indian Journal of Palliative Care, 21(1), 61.

Jafari, N., Farajzadegan, Z., Zamani, A., Bahrami, F., Emami, H., \& Loghmani, A. (2013). Spiritual well-being and quality of life in Iranian women with breast cancer undergoing radiation therapy. Supportive Care in Cancer, 21(5), 1219-1225.

Keating, N.L., Weeks, J.C., Borbas, C., \& Guadagnoli, E. (2003). Treatment of early stage breast cancer: Do surgeons and patients agree regarding whether treatment alternatives were discussed?. Breast Cancer Research and Treatment, 79(2), 225-231.

Ku, Y.-L. (2005). Spiritual distress experienced by cancer patients-Develop a spiritual care for cancer patients, 221-223.

Lu, D., Fall, K., Sparén, P., Ye, W., Adami, H.-O., Valdimarsdottir, U., \& Fang, F. (2013). Suicide and suicide attempt after a cancer diagnosis among young individuals. Annals of Oncology, 24(12), 3112-3117.
Manning-Walsh, J. K. (2005). Psychospiritual well-being and symptom distress in women with breast cancer. In Oncology Nursing Forum, 32, E56). Oncology Nursing Society.

Monod, S.M., Rochat, E., Büla, C.J., Jobin, G., Martin, E., \& Spencer, B. (2010). The spiritual distress assessment tool: An instrument to assess spiritual distress in hospitalised elderly persons. BMC Geriatrics, 10(1), 88. http://doi.org/10.1186/1471-2318$10-88$.

Muhsin. (2011). Kajian identifikasi permasalahan Kebudayaan Sunda. Bandung: Universitas Padjadjaran.

Nur'aeni, A., Ibrahim, K., \& Agustina, H.R. (2013). Makna spiritualitas pada klien dengan sindrom koroner akut. Jurnal Keperawatan Padjadjaran, 79(1).

Puchalski, C., Virani, R., Otis-Green, S., Baird, P., Bull, J., Chochinov, H., et al. (2009). Improving the quality of spiritual care as a dimension of palliative care: The report of the consensus conference. Journal of Palliative Medicine, 12(10), 885-904.

Robins, J.L.W., McCain, N.L., Elswick, R.K., Walter, J.M., Gray, D.P., \& Tuck, I. (2013). Psychoneuroimmunology-based stress management during adjuvant chemotherapy for early breast cancer. Evidence-Based Complementary and Alternative Medicine, 2013.

Siregar, A.R., \& Muslimah, R.N. (2014). Gambaran kualitas hidup pada wanita dewasa awal penderita kanker payudara. Psikologia: Jurnal Pemikiran Dan Penelitian Psikologi, 9(3).

Vance, D.L. (2001). Nurses' attitudes towards spirituality and patient care. Medsurg Nursing, 10(5), 264.

Walton, J. (2002). Finding a balance: A grounded theory. Study of Spirituality in Hemodialysis Patients, 29(5), 447-458.

WHO. (2012). Breast cancer statistics. Retrieved from https://www.wcrf.org/int/ 
Puji Lestari : Spiritual Distress in Breast Cancer Patients

cancer-facts-figures/data-specific-cancers/ breast-cancer-statistics.

Yuniarta, E., \& Suharto, G. (2011). Hubungan tingkat pendidikan pasien terhadap kepuasan pemberian informed consent di bagian bedah RSUP DR. Kariadi Semarang (Mei-Juni 2011). Faculty of Medicine. 